\title{
FROM PROTOTYPE TO RED PRINT: \\ A STUDY ON THE PRIMARY SOURCE IN YUSHUTANG \\ CONGSHU OF THE TEST PROCEDURE OF THE NEW WOOD \\ BLOCK PRINTED BOOKS IN THE LATE QING DYNASTY"
}

\author{
Chen Zhenghong, Chinese Classics Research Institute, Fudan \\ University
}

\begin{abstract}
The carving and printing procedure of the ancient Chinese books, especially the working details that really existed in the traditional Chinese society, has not been fully discussed due to lacking of proper historical documents. This article investigates the test printing procedure of the new wood block printed book in the late Qing Dynasty, based on the Yushutang congshu (Collection of Yushutang) that edited and published by Scholar Shen Shandeng. Through a series of examples, the writing restores every important part in the carving and printing procedure approximately, as well as sorts out primary sources of the Chinese printing history that hide in the Yushutang congshu.
\end{abstract}

\section{KEYWORDS}

Prototype

Red print

Yushutang congshu

Shen Shandeng

Carving and printing procedure of the ancient Chinese books

Wood block printing is the most common way on the publishing of ancient Chinese books, and its basic procedure has been discussed by Lu Qian (卢前) as early as $1940 \mathrm{~s}^{1}$. In the late $20^{\text {th }}$ century, get help from some organizations which still publish ancient Chinese books with former wood blocks, Dr Tsuen Tsien-hsuin (钱存玔) make a further study in his masterpiece Paper and Printing, which was included in Science and Civilisation in China ${ }^{2}$. However, as a result of lacking of historical documents, the carving and printing procedure of the ancient Chinese books, especially the working details, has not been fully investigated by the academic circle, and it's hard to find any other achievement of research in the relevant topics over past two decades.

On this question, the prototype and red print of Yushutang congshu (豫㤎堂从书, Collection of Yushutang), edited and published by Scholar Shen Shandeng 
(沈善登), can provide sufficient and important evidence. Fortunately, the ancient book is preserved by the Shanghai Library. Combine with other prototypes of ancient Chinese books, we can make a further and detailed study, from "xieyang" (写样, means prototype) to "hongyin" (红印, means red print), on the carving and printing procedure of the ancient Chinese books in the late Qing Dynasty, in other words, the test printing procedure of the new wood block printed book. Moreover, Yushutang congshu contains considerable record on the publishing industry in the late Qing Dynasty, such as the cost of wood block carving, the method of word count per page, and the dispute between the publisher, the penman of prototype and the craftsman of carving. It is no doubt to say that, all of these can become the primary historical source for Chinese printing history.

\section{YUSHUTANG CONGSHU (COLLECTION OF YUSHUTANG) AND SHEN SHANDENG}

The prototype and red print of Yushutang congshu is well-preserved in the Shanghai Library, it's a collection of 21 titles ( 25 volumes), included prototypes of 14 titles (seventeen volumes) and red prints of seven titles (eight volumes). It's important to point out that in the prototypes of fourteen tiles, twelve are monographs and the rest are collections.

Shen Shandeng (1830-1902), the editor and publisher of Yushutang congshu, was a scholar of the late Qing dynasty. His courtesy name was Gucheng, and his pseudonym was Weihuan Daoren. He passed his Jinshi degree in 1868, and entered the Hanlin Academy. Under the instruction of Zhong Wenzhen, Shen studied Chunjiu guliangzhuan in his early life, and he also focused on the studies of Buddhism and Western knowledge. In his old age, he changed his academic direction, focusing on Yi-ology. Shen was a book collection master and publisher, it seems that he tried to edit Yushutang congshu volume 2, but the book had not been completed. Among Shen Shandeng's collected works are Zhengxin ji in eight juan, Xushi Miaoyan in ten juan, Bao'en Lun in two juan, Jin Yapian Siyi in one juan. He lived in the Shanghai's American Settlement in his later life, until his death in $1902^{3}$.

\section{PROCEDURE OF MAKING PROTOTYPE IN YUSHUTANG CONGSHU}

Based on prototypes of fourteen books preserved in Yushutang congshu, we can find out the procedure for making a prototype in the late Qing Dynasty consisted of three steps: "Faxie", "Jiaokan" and "Gebu". 
“FAXIE" (START WRITING THE SAMPLE)

“Faxie" (发写) is the first step of making a prototype. It means that the publisher gives the manuscript to the penman of prototype, and the penman will write it down with specific papers. Finally, the product of the penman will become the sample for the carving of wood blocks. In the case of Yushutang congshu, the penman used a kind of red-printed quadrangular paper, with ten columns in every half page and twenty one grids in every single line. For the main text, every single column has three beelines, plus a centre line to divide the grid equally. We can also find a centre line between line and line, and it should be the actual frame that the craftsman carved on a wood block. One thing worth point out is that, besides the centre line, some quadrangular papers have two more straight lines to break up the grid into four equally divided parts. One of the examples is the Xixiang wuju zhaji that well-preserved in the Fudan University Library. These straight lines can ensure that the handwriting of the penman will be written in a regular form, especially when the text should be carved on double lines (i.e. half grid) in small font.

\section{“JIAOKAN" (EMENDATION)}

After the penman finished the writing of the sample for carving, he will give the sample back to the publisher, and then the second step "Jiaokan" (校勘) will begin. "Jiaokan" may be more than one time, and sometimes the publisher will make an extra check even though the re-emendation has been completed. Shen Shandeng and his friends are responsible to take the work as this stage, and the result of the emendation can be found in two forms: upper marginalia and inserted memorandum. According to Shen Shandeng's remark that we can find on the first page of Dushu zalu (读甫杂录), the difference between upper marginalia and inserted memorandum is as follow:

"Finished the first emendation on 23 March (Lunar calendar), please recheck it. If some writing errors or missing characters have been found in the text, just make comments at the upper margin of the page. If there is anything needs discussion, please write a memorandum."

In other words, upper marginalia is used for obvious correction, while memorandum is used for general discussion.

Either emendation or re-emendation, the objective is to examine the text, find out the writing errors or missing characters in text, and correct the format or font face. One of the examples of format correction can be found in a memorandum that attached at the end of the preface of Haiwai xinshu (海外新书, the preface is written by Qian Yong in 1836): 
"This preface is not written in the original format, double space and space have not been used in the correct form. Did the penman find out the problem when they were writing?"

For the correction of font face, Shen Shandeng and his friends focused on the naming taboo (especially taboo against using the personal names of Qing emperors) and character style. Two examples of the former situation can be found in $\mathrm{Ji}$ nan shiyou tanji (济南师友谈记), we can find a upper marginalia on page 15 (second half) pointed out that in column 4, the character of "Li" (暦) “should omit the final stroke". In page 28 (first half), there is another upper marginalia to remind the penman, the character of "Min" (旻) "should omit one stroke." Furthermore, an example of the latter situation can be found in Maoyu Shihua (耄余诗话), the character of "Gui" (癸) contained clerical error, so the editor used a blue pen to write the correct font style at the upper margin of the page.

\section{“GEBU” (CUT AND PASTE)}

The final step of making prototype is “Gebu” (割补), it means that the penman will follow the result of emendation to make correction in specific pages.

We usually believe that when several errors have been found in the prototype, the publisher may use the cinnabar and the ceruse to correct the error, or simply ask the penman to write a new sample. However, Yushutang congshu show us another impression, the actual fact is that, the publisher kept the prototype to the greatest extent possible. One of the examples is the Xiyu xingchengji (西域行程记) in Duwuyuan congchao (独梧园从钞), we can find a piece of quadrangular paper at the upper margin of page 2 (first half), and compare with the content on the page, we could understand that such a piece of paper is used to replace a writing error that the penman had made a mistake on a place name "Wangzizhuang” (王子庄). According to this example, we can know that use a piece of quadrangular paper to replace the writing error is the main method of correcting partial error.

If the numbers of words that need to be added or to be deleted are not just a few words, the editor may use the method of "Gehang" (割行, cut off the paper between line and line) to treat the problem. The function of "Gehang" is to cut off the whole line that is superfluous, as well as cut off the paper to add an extra line. Sometimes, this "cut and paste" process is not easy to understand, the editor will use an extra quadrangular paper to give a detailed explanation to the penman. For instance, a page of green quadrangular paper can be found in the Maoyu shihua. The format of this green paper is just same as the original red-printed quadrangular paper, and it contains a detailed "cut and paste" plan that suggested by the editor after emendation.

In conclusion, there are three main points in the final step of making prototype. Firstly, "Gehang" is to cut off the line out of the boundary of words. Secondly, the 
part that contains error would be removed in the process of "Gehang", and the editor will embed a piece of revised quadrangular paper (often in similar size with the cut-off part) to replace the original part, and then adhere it with a larger paper at the rear side of the page. Finally, if the correction involves a large area, the editor will cut off the paper inside the frame of the block, and a revised sample could be adhered at the top and the bottom of the original page directly (see Figure 1).

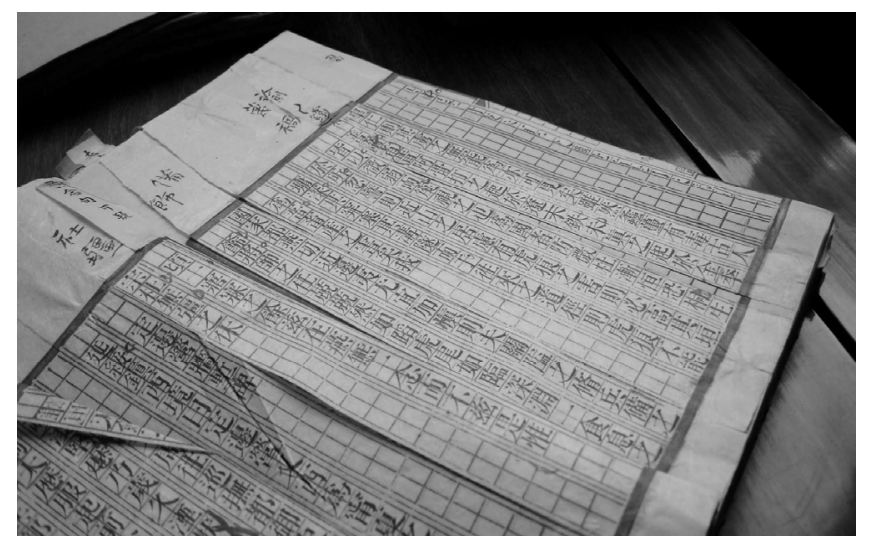

Figure 1

\section{PROCEDURE OF MAKING RED PRINT IN YUSHUTANG CONGSHU}

Once the editor finalizes the prototype, the wood block carving would be started. After the carving of wood block has been finished, the publisher will try to print out one set for emendation at this stage. Based on red prints of seven books preserved in Yushutang congshu, we can find out that the procedure of making red print in the late Qing Dynasty consists of four steps: "Test print", "Emendation on the red print", "Modification to the wood block" and "Partial re-test-print".

\section{TEST PRINT}

In the tradition of publishing Chinese ancient book, people always use the red ink for the printing of test print, so we called it "red print" in Classical Chinese philology, and such a test print can also known as “Juanyang” (镌样) in Yushutang congshu, which means the sample of wood block printing.

If we observe the red prints preserved in Yushutang congshu carefully, it seems that the red prints contain two types of red color: one is similar to tangerine red, like a type of paint that called "Yingzhu Taodan" (银朱桃丹) in the past", and the another one is similar to purplish red, like a type of paint that commonly used in 
the red print in the late Qing Dynasty. This kind of purplish red can also known as "Yanghong" (洋红), which means "Western red" in Chinese, it may imply that the paint is an imported good.

\section{EMENDATION ON THE RED PRINT}

The objective of this step is to examine the carving errors and correct the irregular font faces. In the title page of Chongzhen yilu (崇祜遗录), we can find a comment made by an editor after finished the emendation on the cover of the red print:

"There are some carving errors in the test print, and some strokes in the particular character have been missed incorrectly. I have examined all the text and make upper marginalia each page, please correct all of the errors and send the revised edition to me."

The example of carving error in Chongzhen yilu can be found on page 9 (second half), the craftsman mistook the character of "Ling" (令, means "order" in Chinese) for the character of "Jin" (今, means "now" in Chinese), so the editor point out that "Jin is the carving error of Ling" at the top of the page. On page 21 (first half), we can find a Chinese character “Hao" (吴) was carved in irregular font face, so there is another upper marginalia to remind the craftsman "the lower part of 'Hao' should be the character 'Tian' (天), the upper horizontal stroke should be shorter" (see Figure 2). The editor also focuses on the broken stroke during emendation, on page 1 (first half), page 3 (second half) and page 36 (second half), we can find broken strokes in the character of "Yin" (印), “Qi” (欹) and “Gu” (骨), so the editor remind the craftsman to replace the broken stroke with complete stroke in these words at the top of each corresponding page.

Sometimes, the editor will find out some problems that should be corrected at the stage of making prototype. One of the examples can be found on page 5 (first half) in Lianhuaji suibi part 1, a rectangular punctuation was added before the word "Sima" (司马) in line 2, and the editor made a upper marginalia at the top of page to explain that "Here is the new start of another passage, don't mix it up". Another example is a sentence between page 14 and 15 in Nishilingshu (楝花䂙䔦笔), the preposition "Yu" (於) have been repeated incorrectly, so the editor wrote the character of "Ji" (及) which has a similar meaning at the top of the page and gave following description:

"Character 'Yu' have been repeated incorrectly, that's why we must replace the first character 'Yu' with character 'Ji'."

The explanation of the correction is that, the publisher consider controlling the publishing cost, therefore, he prefers to modify the original text rather than make a new wood block. 


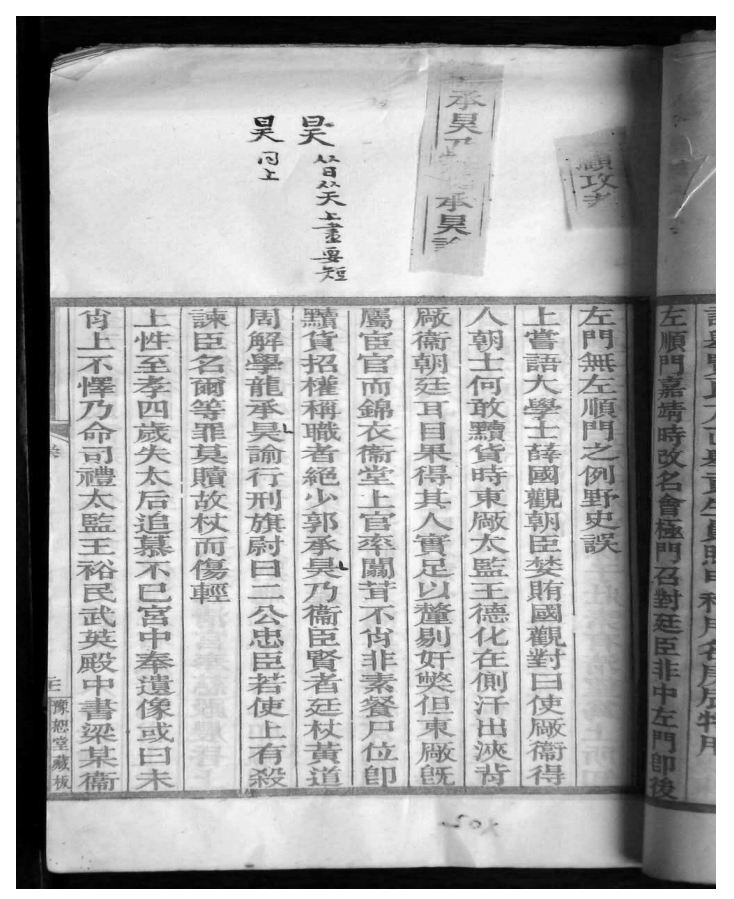

Figure 2

\section{MODIFICATION TO THE WOOD BLOCK}

The craftsman will receive the revised red print from the editor after emendation, and he must try to make modification to the wood block. In Yushutang congshu, the main method of the modification is called "Qianbu" (嵌补), which means embed a new part in Chinese. On the first page of Nishilingshu (倪石陵㠶), as a result of the craftsman forgot to make abbreviations of the book in the centre line of every wood block, the editor write the following comment at the upper margin of the page:

“The character of Ni (倪) must be shown in the centre area of every wood block, please try to "Kanbu" page by page."

We can understand the concrete process of "Qianbu" through the experience of the extant publishing house Jinling kejingchu (Jinling Buddhist Press), it consists of three steps: Scrape part of the wood block, put glue on the wood block and embed a new part in the original position. 


\section{PARTIAL RE-TEST-PRINT}

After the modification to the wood block has been completed, the publisher will try to make a partial test print, that is to say, only the revised part of the wood block is necessary to be reprinted. Since most of the modifications are focused on carving error in one or two characters, this kind of partial test print often uses a small piece of paper to reprint the revised part. For example, we mentioned that the character of "Hao" was carved in irregular font face on page 21 (first half) in Chongzhen yilu, and in fact we have found a small piece of paper attached with this page. Compared the character "Hao" (吴) that printed on this paper with the original one, the upper horizontal stroke is obviously shorter than the lower horizontal stroke. We can also find out a small piece of paper on page 1 (first half) and page 36 (second half) that contained carving error (broken stroke) in the same book, and both of the paper have shown the completed character font face. In the case of missing abbreviations of the book in Nishilingshu we have mentioned in the former section, we can find a small piece of paper, which have a red character "Ni" being printed in the center line of two halves, attached with the first page of the book.

\section{OTHER PRIMARY SOURCES IN THE YUSHUTANG CONGSHU}

Besides the detailed carving and printing procedure of the new wood block printed book in the late Qing Dynasty, Yushutang congshu also contains other primary sources of the Chinese printing history, such as the cost of wood block carving, the method of word count per page and the dispute between the publisher, the penman of prototype and the craftsman of carving.

\section{THE COST OF WOOD BLOCK CARVING}

In the red prints of seven books preserved in Yushutang congshu, four of them have the record of the total number of carved words and the cost at the last page with text and the back flyleaf. For instance, the craftsman made a remark in the back flypage of Nishilingshu, remind the publisher that "this book contains total 38 pages and 15,129 words, so the cost of wood block carving should be 15,129 'wen' (Chinese currency)".

One thing worth point out is that, we have found a letter to Shen Shandeng, written by a crasftman called $\mathrm{Mu}$ zimei, attached with the red print of Zhoulijie (周礼解). Here is the translation of the letter (see Figure 3): 


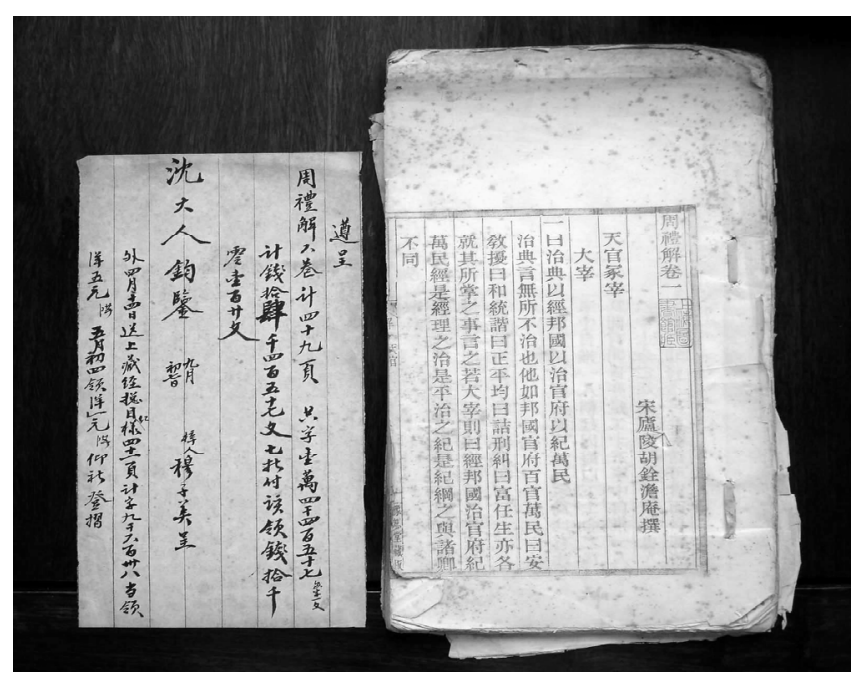

Figure 3

"Attached please find the Zhoulijie of six juan, it contains total 49 pages and 14,457 words (one 'wen' per word), so the cost of wood block carving should be 14,457 'wen'. You can enjoy a $30 \%$ discount, so the amount now owed is 10,120 'wen'.

To Mr Shen, $7^{\text {th }}$ of September (Chinese calendar), written by $\mathrm{Mu}$ zimei, the craftsman.

p.s. I have sent the red print of Cangjing zongmu to you on $14^{\text {th }}$ of April, the book contains total 41 pages and 9,638 words, and the cost should be five "yang yuan" (always mean western silver coin). Please be informed that I have got one "yang yuan" on $4^{\text {th }}$ of May."

It seems that it is similar to a sample business letter, but the "discount" that the craftsman offered to Shen Shandeng is not really a benefit, and we will try to explain this in the next part.

\section{THE METHOD OF WORD COUNT PER PAGE}

We have found that the craftsman usually used a set of secret codes to record the word count per page in the prototypes and red prints of Yushutang congshu. Based on the prototype of Haiwai xinshu that has a relative accurate word count, and other prototypes or red prints which the craftsman used both of the secret codes and Chinese numbers to count the total number of words, we try to sum up the secret codes that can be used to represent number 0 to 9 in Yushutang congshu (We also record another written form of number 1 to 3 and number 6 in the brackets): 


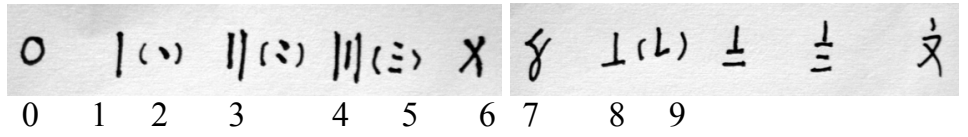

Generally, the total number of words per page in Yushutang congshu, included the abbreviation of the book, chapter number, page number and the public notice "Yushutang cangban" (豫㤎堂藏板) in the centre area of the wood block, should be a three- digits number. The penman or the craftsman will record the total number of words either in vertical column from top to bottom, or in horizontal row from left to right. One of the examples can be found in juan four (page 13) of Haiwai xin$s h u$, this page contains total 420 words in the main text and total nine words in the centre area of the wood block, therefore, the penman marked $x=\neq$ in horizontal row from left to right on the page.

However, after we make a further study to the word count per page, we find that the record of the penman or the craftsman is not often equal to the actual total number of words per page.

For example, in the prototype of Shanghan weizhilun (伤寒微旨论), we can find the total number of words per page in two ways: the penman recorded the result in the centre area of the wood block with secret codes, while the editor recorded the total number at the top of the page with Chinese numbers. In most cases, there is difference between the record of penman and the record of the editor. One of the examples is the total number of words on page 7 in Shanghan weizhilun, juan shang. Actually, this page contains total 426 words, and it is equal to the record of the editor. However, the record of penman is $x_{N}:$, which means that the page contain total 432 words.

It is not a special case. In the letter written by a craftsman called Mu zimei we have quoted in the former section, Mu told Shen Shandeng the red print of Zhoulijie "contains total 49 pages and 14,457 words". We tried to count the total number of words of the book page by page, and found that Mu had not told the truth. We suspect $\mathrm{Mu}$ falsified the record occasionally, just like the secret code in juan three page 8 should be around 200 words, but Mu marked total 302 words at the bottom of the page, next to the original record abandoned by him. Although $\mathrm{Mu}$ zimei stated that Shen Shandeng could enjoyed "a 30\% discount", we find that the record of the craftsman still bigger than the actual total number of words. For instance, the secret code on juan five page 6 is total 236 words, after "a 30\% discount", the record (165 words) is still bigger than the actual total 129 words.

Sometimes, the publisher is hard to know the actual total number of words per page. It is because the penman or the craftsman often uses a set of secret codes to mark the record, and also claims that the publisher can enjoy some discount. Even though Shen Shandeng and his friends had checked the total numbers of words in Shanghan weizhilun, and he felt disappointed on the double charge of the carving of preface in some red prints (we will discuss it in next part), he may not discover that he haven't get any benefits in the offer of "a 30\% discount". 


\section{DISPUTES BETWEEN THE PUBLISHER, THE PENMAN AND THE CRAFTSMAN}

Through the comment made by Shen Shandeng in Yushutang congshu, we can also find some disputes between Shen and the penman or the craftsman. One of the examples can be found in the prototype of Zhangshi yishu (章氏遗书), Shen complained the penman on the flyleaf in front of the book:

"I have requested the penman to delete the line of words with the symbol $L$ at top again and again since two months before. Now, the penman still forgets to delete the line, does it mean that he hasn't pay attention to my comment? We must return the sample to the penman, and ask him to delete the superfluous part before re-emendation."

Besides the compliant to the penman, Shen Shandeng also felt disappointed to the double charge of the carving of preface in some red prints. We can find the remark "Shuangsuan" (双算, means double count in Chinese) on the preface of Zhoulijie (written by Zhu Wenzao in 1787) and the preface of Chongzhen yilu at the bottom of the page. Shen made a criticism on the second page of the preface of Chongzhen yilu:

"Have you ever heard that the total number of words of an original preface in a book should be double counted? If the book contains three different prefaces, does it mean all of them should be double counted? It's really nonsense!"

In conclusion, Shen Shandeng had not finished the publication of Yushutang congshu. We may never know the reason why he gave up, but we guess that the conflict between him, the penman and the craftsman could make him feel exhausted and discouraged. Although Yushutang congshu is an incomplete work, the collection is still a precious historical document in the study to the carving and printing procedure of the wood block printed book in the late Qing Dynasty. Also, the work of Shen Shandeng and his friends will become an unforgettable part in Chinese printing history.

\section{REFERENCES}

1. Shen Shandeng, Edit. Yushutang congshu (豫㤎堂从书, Collection of Yushutang) of [2] 1 Titles. Prototype and Red Print, the Period of Guangxu, Qing Dynasty.

3. Shen Shandeng, Zhengxin ji (证心集) in 8 juan. Hand Copy.

4. Shen Shandeng, Xushi miaoyan (需相眇言) in 10 juan. Printed by Yushutang, the Period of Guangxu, Qing Dynasty.

5. Liu Shiheng (刘世珩), Xixiang wuju zhaji (西相五居湁记) in 1 juan. Manuscript.

6. Liu Shiheng, Xixiang wuju zhajiin in 1 juan. Prototype. 
7. Yan Chen (严辰), Edit.County Annals of Tongxiang in Guangxu Period (光绪桐乡县志) in 24 juan, County Annals of Zhejiang Area of Chinese Collection of Local Chronicles (中国地方志集成 浙工府县志辑) volume 23, Jiangsu Ancient Books Publishing House, Shanghai Bookstore, Bashu Book House.

8. Luqian (卢前), Luqian biji zachao (卢前笔记杂耖, Various Writing of Luqian), Zhonghua Book Company, 2006.

9. Wang Xinfu (王欣夫), Yishuxuan qiecun shanben shulu (蛾术轩策存善本书录, Catalog and Introduction to Chinese Ancient Rare books in Yishuxuan), Shanghai Ancient Books Publishing House, 2002.

10. Tsuen Tsien-hsuin (钱存训), Paper and Printing, in Science and Civilization in China (中国科学技术史:纸与印刷), edited by Joseph Needham, Chinese Edition, Science and Technique Publishing House and Shanghai Ancient Books Publishing House, 1990.

11. Tsuen Tsien-hsuin, Chinese Paper and Printing: A Cultural History (中国纸与印刷文化史), Guangxi Normal University Press, 2005.

\section{NOTES}

* The writing of this article is supported by Program for New Century Excellent Talents in University of Ministry of Education of the People Republic of China and the first group of research projects of National Institute for Advanced Humanistic Studies at Fudan University. Also, I wish to express my sincere gratitude to Mr Chen Xianxing (陈先行) and Mr Liang Ying (梁颖) of the Shanghai Library, Mr Wang Liang (王亮) of the Fudan University Library, for their support and inspiration of this article.

1. Lu Qian, Shulin biehua (书林别话, Some talks on the sector of books), in Luqian biji zachao (Various Writing of Luqian). Beijing: Zhonghua shuju, 2006.

2. Tsuen Tsien-hsuin, Paper and Printing, in Science and Civilization in China, edited by Joseph Needham, Chinese Editon, pp. 174-178. A similar state by Tsuen also in his Chinese Paper and Printing: A Cultural History, pp.176-181. Other Scholars' related research, no more cite here.

3. This introduction to Shen Shandeng's life is based on the description of $\mathrm{Mr}$ Wang Xinfu, Yishuxuan Qiecun Shanben Shulu (Catalog and Introduction to Chinese Ancient Rare books in Yishuxuan), record in Guangxu Tongxiang Xianzhi (County's Annals of TongXiang in Guangxu Period), as well as Shen's collected works such as Zhengxin ji and Xushi Miaoyan.

4. Lu Qian, Shulin biehua (Some talks on the sector of books) in Luqian biji zachao, p. 474. 


\section{ABOUT THE AUTHOR}

Chen Zhenghong, is Professor of Ancient and Rare Books Sorting out and Researching Institute in Fudan University, Shanghai, and also professor of China Ancient Literature Research Center. His research fields are concentrated on the Science of Editions and Bibliography, Science of Literature Document, Science of Art Literature etc. He has published the books of "Chronicle of Mr. Shen Zhou", "Research History of Poetry and Literature in Ming Dynasty (1368-1911 A.D.)", "A Brief History of China's Ban Books", "An Annotate on China's Famous Works of Literature" (Co-author), "Brief Account on the Identification of Ancient and Rare Chinese Printed Books" (Co-author) etc. 